\title{
HIV-Related Neurocognitive Disorders and Drugs of Abuse: Mired in Confound, Surrounded by Risk
}

\author{
Cheryl A. Kennedy • Erin Zerbo
}

Published online: 15 June 2014

(C) Springer International Publishing AG 2014

\begin{abstract}
It has long been known that human immunodeficiency virus (HIV) uses the central nervous system (CNS) as a reservoir and nursery to replicate; therein, it does damage to cells and creates an inflammation that in turn allows for more virus to pass the blood-brain barrier. The inflammatory process itself can cause considerable damage. Neurocognitive disturbance from HIV infection is also known to occur at any stage of the infection. Likewise, common drugs of abuse also have adverse neurocognitive effects on their own. This review examines the literature available to try to elucidate the mechanisms of neurocognitive disorders in the HIV-infected individuals who have used drugs of abuse. Although the incidence of HIV-associated dementia (HAD) has decreased with the advent of highly active anti-retroviral therapy, less severe forms of neurocognitive impairment persist, even with supported immune systems and undetectable viral loads. Considerations for prevention are discussed.
\end{abstract}

Keywords HIV · Human immunodeficiency virus · HAND · Substance use disorders · Cognitive disorders and HIV . Cognitive disorders $\cdot$ Macrophages $\cdot$ Drugs of abuse . Cocaine-induced $\cdot$ Methamphetamine-induced $\cdot$ Alcohol use/abuse $\cdot$ Morphine $\cdot$ Cannabis $\cdot$ Stimulants $\cdot$ Alcohol and cognition · Club drugs and HIV - Club drugs and cognition . Methadone - Psychostimulants · HIV-1 associated dementia . Neurocognitive impairment · HIV and co-morbidity · Neuro-pathogenesis HIV · Blood-brain barrier · Dopamine · Executive functions $\cdot$ Sensorimotor cortex $\cdot$ Basal ganglia .

\section{A. Kennedy $(\bowtie) \cdot$ E. Zerbo}

Department of Psychiatry, Behavioral Health Sciences Building

F Level, Rutgers New Jersey Medical School,

183 South Orange Avenue, Newark, NJ 07101, USA

e-mail: kennedy@njms.rutgers.edu

E. Zerbo

e-mail: eaz19@njms.rutgers.edu
Frontal striatal $\cdot$ Apoliproprotein $\cdot$ Verbal reasoning $\cdot$ Reaction time $\cdot$ Attention deficits $\cdot$ Working memory $\cdot$ Hepatitis $C$. Cognitive rehabilitation

\section{Introduction}

It has been known from early on in the current pandemic that human immunodeficiency virus (HIV) infects cells associated with the central nervous system (CNS) and that the CNS serves as a viral reservoir, even with effective combination anti-retroviral therapy (ART) $[1,2]$. While the incidence of HIV-associated dementia (HAD) has decreased, HIVassociated neurocognitive disorders (HAND) are, and will continue to be, a significant public health problem, particularly where treatment is harder to access. It is thought that $15 \%$ of those with HIV have a related dementia, and anywhere from 30 to $60 \%$ have less severe cognitive impairment [3, 4]. From onset of infection, HIV stows away in immature monocytes to cross the blood-brain barrier, and it is thought that its replicating presence in the brain triggers a cascade of inflammatory reactions that include toxins damaging to the microvascular endothelium that can further disrupt the blood-brain barrier [5-7]. This inflammation causes HIV encephalitis, the primary infection of HIV that continues to chronically fester, even in those with undetectable viral loads and adequate immune markers $[1,8 \bullet]$. HIV protein gp120 not only inhibits stem cells in the brain from producing new nerve cells [7], but in neuronal cells, gp120 induces caspases, mitochondrialdeath proteins that may influence the up-regulation of the death receptor Fas, leading to apoptosis [9].

HIV proteins gp120 and Tat can bind to and interfere with the dopamine transporter (DAT) system and increase both dopamine levels and oxidative stress in the brain, which leads to further dysfunction and impairment $[10 \bullet \bullet, 11 \bullet]$. Substances of abuse, like cocaine, methamphetamines, and opioids, 
commonly used by HIV-positive individuals, can also increase oxidative stress, increase blood-brain barrier permeability, and worsen the neurotoxic effects of gp120 [11•]. Dopamine levels are increased in the brain from most drugs of abuse [12-15]. This exposure increases dopamine well beyond the levels derived from more natural satisfactions like food and sex [16-19]. Dopamine has been clearly shown to induce HIV replication, and researchers have found that dopamine-mediated mechanisms involved in HIV replication may depend on the stages of HIV life-cycle, starting with viral attachment to dendritic cells, monocytes, and lymphocytes through HIV reverse transcription to HIV transcription $[10 \bullet \bullet$, providing researchers with another moving target.

\section{HIV-Associated Neurocognitive Disorders}

HIV alone can induce neurocognitive and neuropsychiatric disorders at almost any point in the infection, whether or not otherwise symptomatic. Even those with good viral suppression and well functioning immune systems can have cognitive problems, from a mild cognitive impairment (MCI) to severe disabling dementia and everything in between [8•]. Individuals with HAND can have motor dysfunction, speech disorders, and behavioral changes, with slow mental processing and poor memory and concentration. Motor problems range from loss of fine motor control to tremors and poor balance. Behaviorally, patients have apathy, lethargy, and reduced emotional responses, with a lack of spontaneity. The brain histopathology of HIV reveals many changes, including neuronal loss and frank structural atrophy $[1,5,20]$.

\section{Cognitive Effects of Drug Use}

Recreational and dependent drug use has long been associated with adverse cognitive effects, both in the short and the long term [21]. Commonly abused substances like alcohol, the opioids, other sedatives, the stimulants, marijuana, or more exotic substances like hallucinogens, combinations, or socalled 'designer drugs,' synthetic cannabinoids, etc., have almost all been associated with either cognitive or neuronal dysfunction or laboratory-derived brain damage on mammals. [22-31].

\section{Confounding and Complicating Factors}

Multiple variables can have adverse effects on cognition, and it is known that the many co-morbid risk factors in HIVpositive individuals have differential effects relative to age, HIV disease severity, and other significant indicators. Researchers have recently found that cognitive risk differs by age, and cognitive reserve capacity (educational attainment or pre-morbid intelligence) is the best predictor of neurocognition [32••]. About $20-25 \%$ of those living with HIV acquired the infection either directly or indirectly because of drug use, whether the virus was blood borne, or sexually or vertically transmitted [33]. Links are clear between substance use and high-risk behaviors in non-injecting drug-using men and women, especially for stimulant users $[34,35 \cdot 36]$. Impaired states influence sexual behavior and lead to risky practices that increase risk of HIV exposure. Injection of drugs can spread HIV, and use of alcohol, stimulants, and other drugs has been associated with disinhibition, risky sexual behaviors, and non-adherence to medical recommendations [37].

Other sources of CNS-mediated signs and symptoms that adversely affect cognition can confound the picture. Many HIV-infected people have psychiatric reactions or exacerbations or psychological responses to being infected (depression, anxiety, agitation, suicidal ideation); others have co-morbid conditions, either acquired or pre-existing, including substance use disorders (SUDs), co-infection with hepatitis $\mathrm{C}$ virus $(\mathrm{HCV})$ or other infections or malignancies [38••]. Individuals around the world with HIV are an aging population and are confronting the chronic illnesses of the older adult, like cardiovascular disease, diabetes, arthritis, neoplasms, dementia, and an even further decline in the immune system that often accompanies old age [32••, 39].

Ellis and colleagues $[4,40]$ found that the historically lowest CD4 count predicts cognitive impairment and is associated with the diagnosis of HAND [41]. ART is considered a positive advancement since it supports and assists the immune system and reduces peripheral viral load; however, there is evidence that the ART used to treat HIV may be responsible for exacerbating common illnesses, especially heart, hepatic, and renal disease [42]. The comorbidities themselves can cause neuro-inflammation that can further worsen cognitive functioning [43]. Aging itself may also contribute to worsening of HIV disease [44, 45]. Some ARTs have greater brain penetration than others and have been associated with hallucinations and other symptoms associated with increased dopamine $[46,47 \bullet]$. While there has been a reduction in incidence of HAD since ART, prevalence remains high and studies show that, despite adequate immune reconstitution and virologic control, cognitive disorders persist in many patients $[48,49]$. It is estimated that over 1 million people in the USA have HAND [50 ], and there is mounting evidence that HIV infection will be the leading cause of early age dementia worldwide $[8 \cdot, 51,52]$. Genetics of the host and the infectious agent also present active variables that affect cognition and may impact whether someone would have dementia without HIV [53•, 54, 55]. There is also evidence that different clades of HIV can have a differential effect on cognition due to differing virulence and pathogenesis [56••]. 
Understanding the intersection of the effects of SUD on cognition in those with HIV infection can be complicated by the frequent use of multiple substances and variable and inconsistent durations of use. Brain polymorphisms can change with drug use, and it has been shown that studies planning to examine genetic risk for HAND in drug users should carefully assess substance use patterns because the neurobiological substrates related to cognition in HIV-positive individuals vary with tonic changes of chronic substance exposure [57].

Neuro-psychological measures for the study of cognition have been standardized over many years and are valid and reliable; however, the study of cognition in drug users with HIV has numerous methodological issues. Quantifying the measurement of actual drug use can be problematic related to poor recall, uneven patterns of use, and, sometimes, lack of full disclosure in self-reported drug use. Multiple drug use is also common, and sorting out what effect is from what substance in poly-drug users presents its own problems. Other complicating co-factors that frequently accompany drug use include lower socioeconomic status, nutritional abnormalities, lower education levels, histories of head injury or other neurological compromise, and higher rates of psychiatric disorders, all of which can complicate interpretation of the effects of drug use [58].

Given this context, herein we review recent relevant literature that has evaluated cognition in those with HIV infection and the effects of specific substances and present the most salient findings.

\section{Drugs of Abuse}

\section{Alcohol}

It is well known that alcohol adversely affects many brain functions, whether when an individual is intoxicated, in withdrawal, or experiencing sustained damage from chronic, heavy use. The behaviorally disinhibiting and judgmentimpairing effects of alcohol can lead to acquisition of HIV or other sexually transmitted infections. Specific cognitive effects are well documented and Wernicke-Korsakoff's dementia was described over 100 years ago in 1897 [59]. Alcohol has some specific preferences for damage to cerebellar and prefrontal structures and the limbic system [60, 61]. HIV itself shows an affinity for structures in the basal ganglia and the associated frontal-striatal pathway [62, 63]. A few studies looked at whether the cognitive effects of both HIV and alcoholism are synergistic and found that those with both disorders are more compromised than those with either HIV or alcoholism alone and found independent adverse effects on cognition from both HIV and alcohol. Patients with both conditions often show greater deficits in visual-spatial perception, verbal reasoning, episodic memory, motor, and reaction times than individuals with either HIV infection or alcoholism alone, and this has suggested a synergistic effect [62, 64-66]. Alcohol-use disorders are common in those living with HIV and in injection drug users (IDUs) and, as is well documented, heavy alcohol use has many adverse effects on people living with HIV, including increased risk of HIV transmission to others by increased risk behaviors, poor retention in care, poor adherence to treatment, impaired ability to suppress HIV, and acceleration of hepatic fibrosis, especially if there is co-infection with HCV and in the setting of prescribed ART [67-70].

\section{Stimulants}

\section{Cocaine}

Many researchers have found that stimulants enhance HIV infection and its progression [71•, 72, 73]. Cocaine increases cell toxicity in astrocytes, accelerates inflammation in microglia, and increases blood-brain barrier permeability [74]. Cocaine-induced neuropsychological impairment is well documented, even though some studies have not supported such deficits. Difference in outcomes has been attributed to varying amounts of cocaine use and methodological differences in testing. Dose-dependent deficits were found in executive functioning, short-term memory, concentration, manual dexterity, psychomotor speed, and visuo-perception, even after weeks of abstinence $[75,76]$.

In HIV-positive individuals, cocaine has clear pathophysiological effects: it increases HIV replication, enhances HIV-infected monocyte movement into the brain, increases the toxicity of certain HIV viral proteins, and accelerates disease progression [77]. While it is fairly clear that either cocaine use or HIV infection independently lead to neurocognitive impairment, study results have been inconsistent in determining an interactive effect of cocaine and HIV infection [78••]. However, Meyer et al. [77] did find significantly impaired verbal learning and memory in HIV-positive daily/weekly crack cocaine users as compared with cocaine-using HIVnegative subjects. However, long-term neurocognitive effects of cocaine in abstinent HIV-positive individuals has not been well studied.

\section{Methamphetamine}

Methamphetamine is highly neurotoxic, resulting in damage to the axon terminals of dopaminergic neurons and depleting both dopamine and norepinephrine, and even leading to a Parkinsonian-like choreatic syndrome in some individuals [79]. HIV infection and methamphetamine use appear to have 
a synergistic effect, and multiple investigators have documented increased neurocognitive impairment in HIVpositive methamphetamine users as compared with control groups. Rippeth et al. [13] and Rodriquez et al. [80] found significantly worse global neuropsychological impairment in a combined HIV/methamphetamine group, and Carey et. al. [81] noted that immunosuppression appeared to also play a role: the worst neuropsychological performance was found in HIV-positive methamphetamine users with $\mathrm{CD} 4<200$ (as compared to less immunosuppressed HIV/methamphetamine users and all nonmethamphetamine HIV-positive users). Carey et al. [81] postulated that synergistic damage to fronto-striatal circuits, which have already been observed separately in HIV and methamphetamine users, could be an explanation for these cognitive deficits.

Imaging studies have revealed reduced hippocampal volume and greater damage to frontal cortex interneurons in HIV-positive methamphetamine users as compared with control groups [76, 82-84]. Reduced Nacetyl aspartate in the anterior cingulate has also been observed [85]. Recently, there has even been evidence for a biologic marker: a specific dopamine receptor D3 polymorphism has been associated with higher rates of cognitive impairment in men with HIV and methamphetamine dependence [86 ${ }^{\circ}$. Among the drugs of abuse, methamphetamine appears to be particularly deleterious for cognition in HIV-infected individuals [71•].

\section{Opioids}

HIV-negative opioid users have significant neurocognitive impairment during regular use and in early withdrawal, including deficits in episodic and working memory, attention, and executive function. These deficits seem to recede when reevaluated in the weeks to months after withdrawal, although a few studies have found persisting impairment in executive function (nonverbal flexible thinking, shifting cognitive sets, planning strategies) or subtle deficits in impulse control [87, 88]. There are less data regarding effects in HIV-positive individuals, but one study of HIV-positive active intravenous heroin and cocaine users did find significant impairment in verbal memory, problem solving, multitasking, visual-motor coordination, and cognitive flexibility [89]. The authors argued that these are important skills for engaging in treatment programs for SUD and HIV, and hence contribute to poorer outcomes for this group. There are also data to suggest that ongoing heroin use is correlated with increased neopterin concentration and hence increased progression to acquired immunodeficiency syndrome (AIDS), which in turn could exacerbate HAND [90]. There is a paucity of research regarding the long-term effects of opioids in subsequently abstinent HIV-positive individuals.
Opioid Substitution Treatment or Medication-Assisted Treatment

In general, individuals receiving methadone maintenance have been found to have impairments in attention, information processing, visual and verbal memory, and problem solving compared with non-opioid-using control groups [79]. HIV infection appears to exacerbate the problem. One study found that even when patients had asymptomatic HIV, the methadone-maintained group was more impaired than the control groups (both opioid-abstinent HIV-positive patients and methadone-maintained HIV-negative patients) [80]. However, a caveat is in order: the methadone-maintained HIV-positive patients were arguably the most burdened group, with fewer years of education, higher viral loads, more significant immunosuppression, and less compliance with antiretroviral regimens. Although causation cannot be established, the authors note that methadone has been found to have immunosuppressive effects in HIV patients and to activate HIV replication in macrophages and microglial cells of the CNS [23].

Most data indicate that individuals maintained on buprenorphine show less cognitive impairment than those receiving methadone, although crossover studies comparing subjects who switch from methadone to buprenorphine and vice versa are needed to more accurately assess independent cognitive effects [91]. Less is known about the effects of buprenorphine on cognition in HIV-positive individuals.

\section{Cannabis}

Studies have not consistently found neuropsychological deficits in HIV-positive long-term users of cannabis, but the varied results may be due to study design [92]. If subjects are included with a history of cannabis use, rather than recent or current use, deficits may have resolved with abstinence. Pope et al. [83] found resolution of neuropsychological impairments after 1 month of abstinence in adult HIV-negative heavy cannabis users. Grant et al. [93] performed a metaanalysis of neurocognitive studies in HIV-negative heavy cannabis users, and found a small negative effect of cannabis in the domains of learning and recall. However, they note that some studies included users who were only abstinent for hours or days, so they may be recording deficits that would have resolved after several more weeks of abstinence. There is a larger concern for persistent deficits in short-term memory and attention in adolescent cannabis users, although these data have not been entirely consistent either [94•, 95, 96].

Cristiani et al. [97] did find poorer performance on memory tasks for daily cannabis users with symptomatic HIV as compared with those with asymptomatic HIV and a sero-negative control group, and the amount of impairment appeared to increase across the stages of HIV disease. The authors 
concluded that cannabis affected users more as the HIV disease progressed; they postulated that subtle effects may become more significant in an immune-compromised person. However, it is important to note that findings were mixed, as researchers did not require a period of abstinence, cannabis use was determined by self-report, and there was not a significant effect on cognitive performance for cannabis users in all groups.

In a group of asymptomatic individuals with HIV, Chang et al. [98] did not find any neuropsychological deficits in cannabis users, although they also failed to find any abnormalities in either HIV or cannabis user control groups. They did document brain metabolite abnormalities in cannabis users, but found that frontal white matter glutamate actually normalized in cannabis-using HIV-positive subjects. Subjects with HIV in this study were mostly asymptomatic, and therefore did not display the well documented deficits seen in later stages of HIV.

\section{Ecstasy/MDMA and other 'Club' drugs}

Methamphetamine, discussed above, is often used in the club or party setting and, as noted, presents multiple risks for users, HIV-positive or not. Methylenedioxy-methamphetamine (MDMA), another popular party drug, affects the serotonin system and can interfere with encoding long-term memory, verbal learning, attention, and concentration [99]. A systematic review of club drug use and HIV infection found that MDMA has an adverse effect on cellular immune responses, can increase cytokine levels and increase viral replication; however, these studies are difficult to perform, often due to multiple substances used and other confounders. Other drugs like gamma-aminobutyric acid can affect sleep and memory, and some evidence points to an increase of dopamine levels in the brain when using [100]. The greatest ongoing risk from club drugs is HIV acquisition or transmission.

\section{Tobacco}

Though not well researched in this context, nicotine has been shown to adversely affect the immune system [101, 102]. Nicotine has been studied in patients with mental illness, and reviewers have found an enhancement of cognition in schizophrenics [103].

\section{Conclusion}

Preventive measures that can ameliorate damage caused by HIV and drugs of abuse are necessary to sustain quality of life and prevent significant morbidity and early mortality in these patients. Prevention strategies must include regular neurocognitive screening during health encounters $\left[38 \bullet^{\circ}\right]$ and targeted and appropriate techniques accounting for differences in gender, age, disease specificity, psychiatric illness, and baseline cognitive status. Harm-reduction methods, lifestyle management, support of cognitive reserve, cognitive remediation therapy, use of ART that provides optimal CNS penetration in hopes of reducing viral load in the CNS, and a research focus that could investigate new compounds to reduce neuroinflammation are all necessary to prevent a looming global crisis of neurocognitively impaired individuals with $\operatorname{HIV}[55,104$, $105 \bullet, 106 \bullet, 107 \bullet \bullet, 108 \bullet \bullet, 109 \bullet \cdot]$.

\section{Compliance with Ethics Guidelines}

Conflict of Interest Cheryl A. Kennedy declares that she is an uncompensated Board member for an Alcohol and Drug Rehabilitation Program. Erin Zerbo declares no conflict of interest.

Human and Animal Rights and Informed Consent This article does not contain any studies with human or animal subjects performed by any of the authors.

\section{References}

Papers of particular interest, published recently, have been highlighted as:

- Of importance

•. Of major importance

1. Lambotte O, Kumaran D, Tardieu M. HIV-1 persistence, viral reservoir and the CNS in the HAART era. Brain Pathol. 2003;13(1):95-103.

2. Clifford DB, Smurzynski M, Park LS, Yeh T, Zhao Y, Blair L, et al. Effects of active HCV replication on neurologic status in HIV RNA virally suppressed patients. Neurology. 2009;73:309-14.

3. Gannon P, Khan MZ, Kolsona DL. Current understanding of HIVassociated neurocognitive disorders pathogenesis. Curr Opin Neurol. 2011;24(3):275-83.

4. Heaton RK, Franklin DR, Ellis RJ, McCutchan JA, Letendre SL, Leblanc S, et al. HIV-associated neurocognitive disorders before and during the era of combination antiretroviral therapy: differences in rates, nature, and predictors. J Neurovirol. 2010;17(1):3-16.

5. Williams KC, Hickey WF. Central nervous system damage, monocytes and macrophages, and neurological disorders in AIDS. Annu Rev Neurosci. 2002;25(1):537-62.

6. Gray F, Adle-Biassette H, Chrétien F, Lorin de la Grandmaison G, Force G, Keohane C. Neuropathology and neurodegeneration in human immunodeficiency virus infection. Pathogenesis of HIVinduced lesions of the brain, correlations with HIV-associated disorders and modifications according to treatments. Clin Neuropathol. 2001;20(4):146-55.

7. Eugenin EA, Clements JE, Zink MC, Berman JW. Human immunodeficiency virus infection of human astrocytes disrupts bloodbrain barrier integrity by a gap junction-dependent mechanism. $\mathrm{J}$ Neurosci. 2011;31(26):9456-65.

8. Simioni S, Cavassini M, Annonti JM, et al. Cognitive dysfunction in HIV patients despite long-standing suppression of viremia. AIDS. 2010;24(9):1243-50. This article fleshes out the problems related to cognitive dysfunction despite apparent virologic control. 
9. Okamoto S, Kang Y, Brechtel CW, Siviglia E, Russo R, Clemente A, et al. HIV/gp120 decreases adult neural progenitor cell proliferation via checkpoint kinase-mediated cell-cycle withdrawal and G1 arrest. Cell Stem Cell. 2007;1(2):230-6.

$10 . \bullet$ Purohit V, Rapaka R, Shurtleff D. Drugs of abuse, dopamine, and HIV-associated neurocognitive disorders/ HIV-associated dementia. Mol Neurobiol. 2011;44:102-10. Well written review that covers the basic science of neurocognitive disorders and how drug use and HIV intersect to cause problems.

11. Silverstein PS, Shah A, Weemhoff J, Kumar S, Singh D, Kumar A. HIV-1 gp120 and drugs of abuse: interactions in the central nervous system. Curr HIV Res. 2012;10(15):369-83. Discusses how HIV proteins cause problems in drug users.

12. Di Chiara G, Imperato A. Drugs abused by humans preferentially increase synaptic dopamine concentrations in the mesolimbic system of freely moving rats. Proc Natl Acad Sci U S A. 1988;85: 5274-8.

13. Rippeth JD, Heaton RK, Carey CL, Marcotte TD, Moore DJ, Gonzalez R, et al. Methamphetamine dependence increases risk of neuropsychological impairment in HIV infected persons. J Int Neuropsychol Soc. 2004;10:1-14.

14. Burdo TH, Katner SN, Taffe MA, Fox HS. Neuroimmunity, drugs of abuse, and neuroAIDS. J Neuroimmune Pharm. 2006;1: 41-9.

15. Ferris MJ, Mactutus CF, Booze RM. Neurotoxic profiles of HIV, psychostimulant drugs of abuse, and the irconcerted effect on the brain: current status of dopamine system vulnerability in NeuroAIDS. Neurosci Biobehav Rev. 2008;32:883-909.

16. Di Chiara G, Bassareo V. Reward system and addiction: what dopamine does and doesn't do. Curr Opin Pharmacol. 2006;7:6976.

17. Pontieri FE, Tanda G, Di Chiara G. Intravenous cocaine, morphine, and amphetamine preferentially increase extracellular dopamine in the "shell" as compared with the "core" of the rat nucleus accumbens. Proc Natl Acad Sci U S A. 1995;92:12304-8.

18. Bradberry CW. Acute and chronic dopamine dynamics in a nonhuman primate model of recreational cocaine use. J Neurosci. 2000;20:7109-15.

19. Walker QD, Kuhn CM. Cocaine increases stimulated dopamine release more in periadolescent than adult rats. Neurotoxicol Teratol. 2008;30:412-8

20. Kallianpur KJ, Shikuma C, Kirk GR, Shiramizu B, Valcour V, Chow D, et al. Peripheral blood HIV DNA is associated with atrophy of cerebral and sub-cortical gray matter. Neurology. 2013;80:1792-9.

21. Nath A, Maragos WF, Avison MJ, Schmitt FA, Berger JR. Acceleration of HIV dementia with methamphetamine and cocaine. J Neurovirol. 2001;7:66-71.

22. Fiala M, Eshleman AJ, Cashman J, Lin J, Lossinsky AS, Suarez V, et al. Cocaine increases human immunodeficiency virus type 1 neuroinvasion through remodeling brain microvascular endothelial cells. J Neurovirol. 2005;11:281-91.

23. Li Y, Wang X, Tian S, et al. Methadone enhances human immunodeficiency virus infection of human immune cells. J Infect Dis. 2002;185:118-22.

24. Gaskill PJ, Calderon TM, Luers A, Eugenin EA, Javitch JA, Berman JW. Human immunodeficiency virus infection of human microphages is increased by dopamine. Am J Pathol. 2009;175: 1148-59.

25. Liang H, Wang X, Chen H, Song L, Ye L, Wang S, et al. Methamphetamine enhances HIV infection of macrophages. Am J Pathol. 2008;172:1617-24.

26. Mahajan SD, Aalinkeel R, Sykes DE, Reynolds JL, Bindukumar B, Fernandez SF, et al. Tight junction regulation by morphine and HIV-1 tat modulates blood-brain barrier permeability. J Clin Immunol. 2008;28:528-41.
27. Dhillon NK, Williams R, Peng F, Tsai Y, Dhillon S, Nicolay B, et al. Cocaine-mediated enhancement of virus replication in macrophages: implications for human immunodeficiency virusassociated dementia. J Neurovirol. 2007;13:483-95.

28. Kuczenski R, Everall IP, Crews L, Adame A, Grant I, Masliah E. Escalating dose-multiple binge methamphetamine exposure results in degeneration of the neocortex and limbic system in the rat. Exp Neurol. 2007;207:42-51.

29. Reynolds JL, Mahajan SD, Bindukumar B, Sykes C, Schwartz SA, Nair MPN. Proteomic analysis of the effects of cocaine on the enhancement of HIV-1 replication in normal human astrocytes. Brain Res. 2006;1123:226-36.

30. Sharma HS, Ali SF. Alterations in blood-brain barrier function by morphine and methamphetamine. NY Acad Sci. 2006;1074:198-224.

31. Anthony IC, Arango JC, Stephens B, Simmonds P, Bell JE. The effects of illicit drugs on the HIV infected brain. Front Biosci. 2008;13:1294-307.

32.• Patel SM, Thames AD, Panos N, Stella E, Castellon S, Hinkin CH. The aggregate effects of multiple comorbid risk factors on cognition among HIV-infected individuals. J Clin Exp Neuropsychol. 2013;35(4):421-34. Elegant study that uses a complicated algorithm and weighting system to assess risk factors for cognition in those with HIV infection.

33. Prevention Services for HIV infection, Viral Hepatitis, Sexually Transmitted Diseases, and Tuberculosis for persons who use drugs Illicitly: Summary Guidance from CDC and the U.S. Department of Health \& Human Services Recommendations and Reports. Nov. 9, 2012/61(rrOS);1-40. www.cdc.gov/mmwr:Integrated. Accessed 17 May 2014

34. Young SD, Shoptaw S. Stimulant use among African American and Latino MSM social networking users. J Addict Dis. 2013;32(1):3945.

35. Rehm J, Shield KD, Joharchi N, Shuper PA. Alcohol consumption and the intention to engage in unprotected sex: systematic review and meta-analysis of experimental studies. Addiction. 2012;107(1): 51-9. Meta-analysis with a review that shows the risk of alcohol and unprotected sexual encounters.

36. Palepu A, Tyndall M, Yip B, O’Shaughnessy MV, Hogg RS, Montaner JS. Impaired virologic response to highly active antiretroviral therapy associated with ongoing injection drug use. J Acquir Immnue Defic Syndr. 2003;32:522-6.

37. Meade CS, Conn NA, Skalski LM, Safren SA. Neurocognitive impairment and medication adherence in HIV patients with and without cocaine dependence. J Behav Med. 2011;34:128-38.

38.• Kennedy CA, Nakata K. HIV-Associated neurocognitive dysfunction (HAND) and related neuropsychiatric complications. AIDSLine, NJDOH; 2010;1-17. Review of HAND-related complications and provides case studies and screening tools.

39. Stoff DM, Khalsa JH, Monjan A, Portegies P. Introduction to HIV/ AIDS and aging. AIDS. 2004; 18:S1-2.

40. Ellis R, Langford D, Masliah E. HIV and antiretroviral therapy in the brain: neuronal injury and repair. Nat Rev Neurosci. 2007;8(1): 33-44.

41. Valcour V, Paul R, Chiao S, Wendelken LA, Miller B. Screening for cognitive impairment in human immunodeficiency virus. Clin Infect Dis. 2011;53(8):836-42.

42. Vance DE, Mugavero M, Willig J, Raper JL, Saag MS. Aging with HIV: a cross-sectional study of comorbidity prevalence and clinical characteristics across decades of life. J Assoc Nurses AIDS Care. 2011;22(1):17-25.

43. Vance D, Larsen KI, Eagerton G, Wright MA. Comorbidities and cognitive functioning: implications for nursing research and practice. J Neurosci Nurs. 2011;43(4):215-24.

44. Kirk JB, Goetz MB. Human immunodeficiency virus in an aging population, a complication of success. J Am Geriatr Soc. 2009;57(11):2129-38. 
45. Valcour VG. HIV, aging, and cognition: emerging issues. Top Antivir Med. 2013;21(3):119-23.

46. Marra C, Zhao Y, Clifford DB, Letendre S, Evans S, Henry K, et al. Impact of combination antiretroviral therapy on cerebrospinal fluid HIV RNA and neurocognitive performance. AIDS. 2009;23(11): 1359-66.

47. Abers MS, Shandera WX, Kass JS. Neurological and psychiatric adverse effects of antiretroviral drugs. CNS Drugs. 2014;28(2): 131-45. Discusses the central nervous system effects of antiretroviral therapy.

48. Sacktor N, Tarwater PM, Skolasky RL, McArthur JC, Selnes OA, Becker J, et al. CSF antiretroviral drug penetrance and the treatment of HIV-associated psychomotor slowing. Multicenter for AIDS Cohort Study (MACS). Neurology. 2001;57(3):542-4.

49. Cysique LA, Brew BJ. Prevalence of non-confounded HIVassociated neurocognitive impairment in the context of plasma HIV RNA suppression. J Neurovirol. 2011;17(2):176-83.

50. McArthur JC, Steiner J, Sacktor N, Nath A. Human immunodeficiency virus-associated neurocognitive disorders: mind the gap. Ann Neurol. 2010;67(6):699-714. Prescient review of HAND.

51. Wright EJ, Nunn M, Joseph J, Robertson K, Lal L, Brew BJ. NeuroAIDS in the Asia pacific region. J Neurovirol. 2008;14(6): 465-73.

52. Ances BM, Ellis RJ. Dementia and neurocognitive disorders due to HIV-1 infection. Semin Neurol. 2007;27(1):86-92.

53. Spector SA, Singh KK, Gupta S, Cysique LA, Jin H, Letendre S, et al. APOE $\varepsilon 4$ and MBL-2 O/O genotypes are associated with nerocognitive impairment in HIV-infected plasma donors. AIDS. 2010;24:1471-9. Points out the genetic differences in HIV-infected individuals that relate to neurocognitive impairment.

54. Morales D, Acevedo SF, Skolasky RL, Hechavarria R, Santiago S, De La Torre T, et al. Translational spatial task and its relationship to HIV-associated neurocognitive disorders and apolipoprotein $\mathrm{E}$ in HIV-seropositive women. J Neurovirol. 2012;18:488-502.

55. Rappaport J, Berger JR. Genetic testing and HIV dementia: teasing out the molecular mechanisms of disease. AIDS. 2010;24:1585-7.

$56 . \bullet$ Tyor W, Fritz-French C, Nath A. Effect of HIV clade differences on the onset and severity of HIV-associated neurocognitive disorders. J Neurovirol. 2013;19(6):515-22. Discusses the different clades of HIV that exist globally and is a harbinger of future global load of dementia in the untreated.

57. Jacobs MM, Murray J, Byrd DA, Hurd YL, Morgello S. HIVrelated cognitive impairment shows bi-directional association with dopamine receptor DRD1 and DRD2 polymorphisms in substancedependent and substance-independent population. J Neurovirol. 2013;19(5):495-504.

58. Durvasula RS, Hinkin CH. Neuropsychological dysfunction among HIV infected drug abusers. Am J Infect Dis. 2006;2(2):67-73.

59. Thomson AD, Cook CC, Guerrini I, Sheedy D, Harper C, Marshall EJ. Wernicke's encephalopathy: 'plus ça change, plus c'est la même chose'. Alcohol Alcohol. 2008;43(2):180-6.

60. Cardenas VA, Meyerhoff DJ, Studholme C, Kornak J, Rothlind J, Lampiris $\mathrm{H}$, et al. Evidence for ongoing brain injury in human immunodeficiency virus-positive patients treated with antiretroviral therapy. J Neurovirol. 2009; 15(4):324-33.

61. Sullivan EV, Pfefferbaum A. Neuroimaging of the WernickeKorsakoff syndrome. Alcohol Alcohol. 2009;44(2):155-65.

62. Fama R, Rosebloom MJ, Sassoon SA, Thompson MA, Pfefferbaum A, Sullivan EV. Remote semantic memory for public figures in hiv infection, alcoholism, and their comorbidity. Alcohol Clin Exp Res. 2011;35(2):265-76.

63. Navia BA, Jordon BD, Price RW. The AIDS dementia complex: I. Clinical features. Ann Neurol. 1986;19:517-24.

64. Green JE, Saveanu RV, Bornstein RA. The effect of previous alcohol abuse on cognitive function in HIV infection. Am J Psychiatry. 2004;161:249-54.
65. Rothlind JC, Greenfield TM, Bruce AV, Meyerhoff DJ, Flenniken DL, Lindgren JA, et al. Heavy alcohol consumption in individuals with HIV infection: effects on neuropsychological performance. J Int Neuropsychol Soc. 2005;11(1):70-83.

66. Sassoon SA, Fama R, Rosenbloom MJ, O'Reilly A, Pfefferbaum A, Sullivan EV. Component cognitive and motor processes of the digit symbol test: differential deficits in alcoholism, HIV infection, and their comorbidity. Alcohol Clin Exp Res. 2007;31(8):1315-24.

67. Baliunas D, Rehm J, Irving H, Shuper P. Alcohol consumption and risk of incident human immunodeficiency virus infection: a metaanalysis. Int J Public Health. 2009;55:159-66.

68. Kim TW, Palepu A, Cheng DM, Libman H, Saitz R, Samet JH. Factors associated with discontinuation of antiretroviral therapy in HIV-infected patients with alcohol problems. AIDS Care. 2007;19: 1039-47.

69. Kim TW, Kertesz SG, Horton NJ, Tibbetts N, Samet JH. Episodic homelessness and health care utilization in a prospective cohort of HIV-infected persons with alcohol problems. BMC Health Serv Res. 2006;6:19.

70. Parsons JT, Rosof E, Mustanski B. Patient-related factors predicting HIV medication adherence among men and women with alcohol problems. J Health Psychol. 2007;12:357-70.

71. Blackstone K, Iudicello JE, Morgan EE, Weber E, Moore DJ, Franklin DR, et al. Human immunodeficiency virus infection heightens concurrent risk of functional dependence in persons with long-term methamphetamine use. J Addict Med. 2013;7:255-63. Discusses the adverse long-term outcomes of amphetamine abuse in those with HIV.

72. Yu Q, Zhang D, Walston M, Zhang J, Liu Y, Watson RR. Chronic methamphetamine exposure alters immune function in normal and retrovirus-infected mice. Int J Immunopharmacol. 2002;2(7):951-6.

73. Everall I, Salaria S, Roberts E, Corbeil J, Sasik R, Fox H, et al. Methamphetamine stimulates interferon inducible genes in HIV infected brain. J Neuroimmunol. 2005;170(1-2):158-71.

74. Kousik SM, Napier TC, Carvey PM. The effects of psychostimulant drugs on blood brain barrier function and neuroinflammation. Front Pharmacol. 2012;3:121.

75. Bolla KI, Rothman R, Cadet JL. Dose-related neurobehavioral effects of chronic cocaine use. J Neuropsychiatry Clin Neurosci. 1999;11(3):361-9.

76. Archibald SL, Jacobson MW, Fennema-Notestine C, Ogasawara M, Woods SP, Letendre S, et al. Functional interactions of HIVinfections and methamphetamine dependence during motor programming. Neuroimaging. 2012;202:46-52.

77. Meyer VJ, Rubin LH, Martin E, Weber KM, Cohen MH, et al. HIV and recent illicit drug use interact to affect verbal memory in women. J Acquir Immune Defic Syndr. 2013;63(1):67-76.

78.• Martin-Thormeyer EM, Paul RH. Drug abuse and hepatitis C infection as comorbid features of HIV associated neurocognitive disorder: neurocognitive and neuroimaging features. Neuropsychol Rev. 2009;19(2):215-31. One of the few articles that tackles HIV, $H C V$, drug use, and neurocognition.

79. Anand P, Springer SA, Copenhaver MM, Altice FL. Neurocognitive impairment and HIV risk factors: a reciprocal relationship. AIDS Behav. 2010;14(6):1213-26.

80. Rodriguez SD, Rodriguez AM, Seoane PG. Neuropsychological impairment among asymptomatic HIV-positive former intravenous drug users. Cogn Behav Neurol. 2006;19(2):95-104.

81. Carey CL, Woods SP, Rippeth JD, Gonzalez R, Heaton RK, Grant I. Additive deleterious effects of methamphetamine dependence and immunosuppression on neuropsychological functioning in HIV infection. AIDS Behav. 2006;10(2):185-90.

82. Jernigan TL, Gamst AC, Archibald SL, Fennema-Nostestine C, Mindt MR, Marcotte TD, et al. Effects of methamphetamine dependence and HIV infection on cerebral morphology. Am J Psychiatry. 2005;162(8):1461-72. 
83. Pope HG, Gruber AJ, Hudson JI, Huestis MA, Yurgelun-Todd D. Neuropsychological performance in long-term cannabis users. Arch Gen Psychiatry. 2001;58:909-15.

84. Langford D, Adame A, Grigorian A, Grant I, McCutchan JA, Ellis $\mathrm{RJ}$, et al. Patterns of selective neuronal damage in methamphetamine-user AIDS patients. J Acquir Immune Defic Syndr. 2003;34(5):467-74.

85. Taylor MJ, Alhassoon OM, Schweinsburg BC, Videen JS, Grant I. MR spectroscopy in HIV and stimulant dependence. J Int Neuropsychol Soc. 2000;6(1):83-5.

86. Gupta S, Bousman CA, Chana G, Cherner M, Heaton RK, Deutsch $\mathrm{R}$, et al. Dopamine receptor D3 genetic polymorphism (rs6280TC) is associated with rates of cognitive impairment in methamphetamine-dependent men with HIV: preliminary findings. J Neurovirol. 2011;17(3):239-47. Points out the genetic polymorphism associated with cognitive impairment in HIV-infected methamphetamine users.

87. Rapeli P, Kivisaari R, Autti T, Kahkonen S, Puuskari V, Jokela O, et al. Cognitive function during early abstinence from opioid dependence: a comparison to age, gender, and verbal intelligence matched controls. BMC Psychiatry. 2006;24:6-9.

88. Pau CW, Lee TM, Chan SF. The impact of heroin on frontal executive functions. Arch Clin Neuropsychol. 2002;17(7): 663-70.

89. Margolin A, Avants SK, Warbutron LA, Hawkins KA. Factors affecting cognitive functioning in a sample of human immunodeficiency virus-positive injection drug users. AIDS Patient Care STDS. 2002;16(6):255-67.

90. Di Franco MJ, Marlink R, Hunter DJ, Tosteson T, Mayer K, Essex M. Association of immune activation with intravenous heroin use and methadone treatment in HIV-1 seropositive and sero-negative subjects. J Acquir Immune Defic Syndr. 1993;6(12):1297-300.

91. Rapeli P, Fabritius C, Kalska H, Alho H. Cognitive functioning in opioid-dependent patients treated with buprenorphine, methadone, and other psychoactive medications: stability and correlates. BMC Clin Pharmacol. 2011;11:13.

92. Byrd DA, Fellows RP, Morgello S, et al. Neurocognitive impact of substance use in HIV infection. J Acquir Immune Defic Syndr. 2011;58:154-62.

93. Grant I, Gonzalez R, Carey CL, Natarajan L, Wolfson T. Non-acute (residual) neurocognitive effects of cannabis use: a meta-analytic study. J Int Neuropsychol Soc. 2003;9(5):679-89.

94. Meier MH, Caspi A, Antony A, Harrington HL, Houts R, Keefe RSE, et al. Persistent cannabis users show neuropsychological decline from childhood to midlife. Proc Natl Acad Sci U S A. 2012;109(40):E2657-64. Long-term study of cannabis users followed from adolescence to mid-life and showing cognitive decline for those who began using as adolescents. Other confounding factors are not well discussed.

95. Medina KL, Hanson KL, Schweinsburg AD, Cohen-Zion M, Nagel BJ, Tapert SF. Neuropsychological functioning in adolescent marijuana users: subtle deficits detectable after a month of abstinence. J Int Neuropsychol Soc. 2007;13(5):807-20.
96. Tait RJ, Mackinnon A, Christensen H. Cannabis use and cognitive function: 8-year trajectory in young adult cohort. Addiction. 2011;106(12):2195-203.

97. Christiani SA, Pukay-Martin ND, Bornstein RA. Marijuana use and cognitive function in HIV-infected people. J Neuropsychiatry Clin Neurosci. 2004;16(3):330-5.

98. Chang L, Cloak C, Yakupov R, Ernst T. Combined and independent effects of chronic marijuana use and HIV on brain metabolites. J Neuroimmune Pharmacol. 2006;1(1):65-76.

99. McCardle K, Luebbers JD, Carter RJ, Croft RJ. Chronic MDMA (ecstasy) use, cognition and mood. Psychopharmacology. 2004;173:434-9.

100. Colfax G, Guzman R. Club drugs and HIV infection: a review. Clin Infect Dis. 2006;42:1463-9.

101. Rock RB, Gekker G, Aravalli RN, Hu S, Sheng WS, Peterson PK. Potentiation of HIV-1 expression in microglial cells by nicotine: involvement of transforming growth factor-beta 1 . J Neuroimmune Pharmacol. 2008;3:143-9.

102. Sopori ML, Kozak W, Savage SM, Geng Y, Kluger MJ. Nicotineinduced modulation of $\mathrm{T}$ cell function. Implications for inflammation and infection. Adv Exp Med Biol. 2008;437:279-89.

103. Weinberger A, Cerissa L, Creeden BS, Sacco KA, George TP. Neurocognitive effects of nicotine and tobacco in individuals with schizophrenia. J Dual Diagn. 2007;3(3-4):61-77.

104. Crystal H, Kelyman I, Anastos K, Lazar J, Cohen M, Liu C, et al. Effects of hepatitis $\mathrm{C}$ and HIV on cognition in women: data from the women's interagency HIV study. J Acquir Immune Syndr. 2012;59:149-54.

105.• Chen L-Y, Strain EC, Crum RM, Mojtabai R. Gender differences in substance abuse treatment and barriers to care among persons with substance use disorders with and without comorbid major depression. J Addict Med. 2013;7:325-34. Points out gender differences in barriers to care for substance-using individuals with and without mental illness.

106. Ho CJ, Preston C, Fredericks K, Doorley SL, Kramer RJ, Kwan L, et al. A unique model for treating chronic hepatitis $\mathrm{C}$ in patients with psychiatric disorders, substance abuse, and/or housing instability. J Addict Med. 2013;7:320-4. Provides a therapeutic approach to managing chronic HCV with SUD, psychiatric disorders, and homelessness.

107.• Hestad KA, Menon JA, Silalukey-Ngoma M, Franklin Jr DR, Imasiku ML, Kalima K, et al. Sex differences in neuropsychological performance as an effect of human immunodeficiency virus infection a pilot study in zambia. Afr Nerv Ment Dis. 2012;200:336-42. Examines gender differences in cognitive outcomes in HIV.

108.• Shapshak P, Kangueane P, Fujimura RK, Commins D, Chiapelli F, Singer E, et al. Editorial NeuroAIDS review. AIDS. 2011;25:12341. Excellent review of the problem.

109.• Persidsky Y, Ho W, Ramirez SH, Potula R, Abood ME, Unterwald $\mathrm{E}$, et al. HIV-1 infection and alcohol abuse: neurocognitive impairment, mechanisms of neuro-degeneration and therapeutic interventions. Brain Behav Immun. 2011;25(Supplement 1):S6170. Discusses the mechanisms of HIV and alcohol damage in the brain and discusses interventions. 